\title{
Trocar-wound in laparoscopic operations; novel approach to prevent hernia
}

\author{
Ayman $M S$ Soliman, $M D$ \\ Department of General Surgery, Ain Shams University Hospital
}

\begin{abstract}
Background: Fascial wound dehiscence and incisional hernia after abdominal surgery is a reported complication. The development of minimally invasive surgical techniques has led to a dramatic decrease in these complications. However, laparoscopic surgery may still be followed by trocar-wound herniation. Various methods have been advocated for its prevention.

Methods: The records of 109 patients who underwent laparoscopic operations (12 gastric bypass, 18 gastroplasty, 15 gastric banding and 64 cholecystectomies) in obese patients between November 2004 and December 2006, with regular follow-up, were retrospectively reviewed. In all patients, the fascial layer of trocar wounds was not closed. Instead, a Surgicel plug was inserted into the muscle layer of trocar wounds.

Results: 2 male patients in the gastric bypass group developed a trocar wound hernia, for an overall prevalence of $1.83 \%$ (2/109). The intervals between surgery and diagnosis were 1 and 3 months respectively. These 2 patients have not developed intestinal obstruction as a consequence of the hernia, and have not undergone hernia repair. No patient in the other groups has been found to develop a hernia.

Conclusion: With Surgicel pluging technique, the prevalence of trocar-wound hernia after laparoscopic procedures has been very rare.

Key words: Trocar wound herniation, laparoscopy, Surgicel ${ }^{\circledR}$
\end{abstract}

\section{Introduction:}

Incisional hernia is an iatrogenic complication of abdominal surgery that has troubled patients and surgeons over the last two centuries, affecting $5-15 \%$ of patients. ${ }^{1-2}$ It is known that the frequency of incisional hernia has decreased greatly with minimal access surgery. ${ }^{2}$ However, laparoscopic technique has resulted in a new operative complication - trocar wound hernia. ${ }^{3}$ Trocar-site hernias following laparoscopic surgery have been reported in approximately $1 \%$ of cases. ${ }^{4}$ Secure fascial closure has been reported to decrease this complication. However, it is often difficult to directly visualize the fascia through these tiny incisions during the standard hand-sutured closure. ${ }^{4}$ Besides, if there is loss of pneumoperitoneum during port-site closure, the laparoscopic monitoring of suture placement is hindered, and there is a risk of nerve entrapment, abdominal wall vessel injury, and bowel injury, especially in obese patients. ${ }^{3-6}$ In this method, Surgicel plug was used to prevent trocar-wound hernia without fascial closure.

\section{Materials and methods: \\ Patients:}

The study population comprised 109 patients undergoing laparoscopic operations as treatment for cholecystolithiasis in 64 patients and for morbid obesity in 45 patients between November 2004 and December 2006 at Ain Shams Specialized Hospital, with regular follow-up. These included patients with gastric bypass $(\mathrm{n}=12)$, patients with gastric banding $(n=15)$, patients with gastroplasty $(n=18)$, and patients with wide fascial wounds after difficult extraction of gall bladder $(n=64)$. The preoperative mean body weight was 89.2 $\pm 23.4 \mathrm{~kg}$ (range 79.0-198.7), and the body mass index (BMI) was $39.4 \pm 7.9 \mathrm{~kg} / \mathrm{m} 2$ (range 39.5-67.0). There were 43 male and 66 female patients with mean age $34.2 \pm 11.4$ years (range 17-56). Patient records were reviewed retrospectively, and those patients who developed trocar wound herniation were identified.

For all patients, the following additional informations were extracted from the patient 
records: medical history, surgical history and smoking history. Also, patients were consented about the use of plug technique instead of the sutures. Standard follow-up for all patients after laparoscopic bariatric operations was within 2 weeks from hospital discharge. Subsequent follow-up was at 3-month intervals in the first year and then annually. Patients who required conversion to an open approach and those who failed to attend for postoperative follow-up were excluded from the analysis.

During the operations, all patients received general anesthesia, orotracheal intubation and were put in the standard position (lithotomy in bariatric procedures and supine in cholecystectomies).

\section{Trocar insertion and wound closure}

The technique of laparoscopic cholecystectomy was through 4 ports in the standard positions while the techniques of laparoscopic gastric bypass, gastroplasty and gastric banding that followed have been detailed and were through 4-5 ports. First, pneumoperitoneum was established via a Veress needle with intra-abdominal pressure up to $15 \mathrm{mmHg}$. The initial trocar was advanced with a continuous motion, applying steady pressure and feeling the spread of fascia, muscle, peritoneum and then into the peritoneal cavity (transperitoneal technique). Other ports were placed under visualization on the video monitor with the same technique. Different brands of disposable trocars (non-bladed and bladed) were employed randomly, with port positioning, as follows:

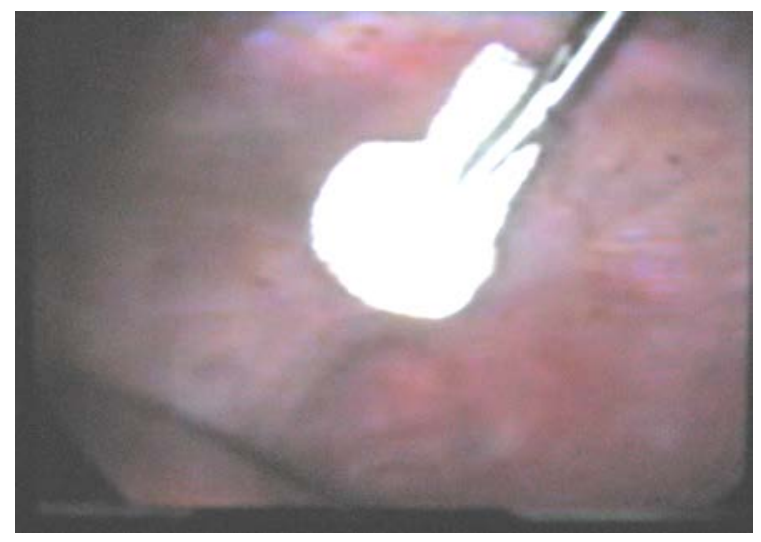

Figure (1A)
1) The laparoscope was placed above the umbilicus, about $20 \mathrm{~cm}$ below the xiphoid process. The initial supraumbilical port was $10-\mathrm{mm}$ for gastric bypass and $15-\mathrm{mm}$ for gastric banding.

2) The surgeon's right and left-handed ports were placed in the right and left midclavicular lines, $2-3 \mathrm{~cm}$ below the costal margins. Two 12-mm ports were used for gastric bypass and two 5-mm ports for gastric banding.

3) The liver retractor was placed in the infraxyphoid area via one $5-\mathrm{mm}$ port.

4) An assistant port (5-mm) was placed at the level of the umbilicus in the left anterior axillary line.

At the end of the operation, the ports were removed under direct vision from the supraumbilical port, to make sure there was no bleeding or entrapment of intraperitoneal tissue. First, we folded a piece of Surgicel ${ }^{\circledR}$ mesh (Johnson \& Johnson, Arlington, TX) as a plug and inserted it into the abdominal cavity via the port Figure(1A). Second, we withdrew the port through the muscle layer slowly to prevent gas gushing out Figure(1B). Third, we retracted the Surgice ${ }^{\circledR}$ plug out and left it inside the muscle layer Figure( $\mathbf{2 A , B})$. Finally, the port was removed. The final location of the Surgicel ${ }^{\circledR}$ plug is shown in Figure(3A,B). All trocar wounds $>10-\mathrm{mm}$ were managed with the same procedure. The subcutaneous layer was closed with interrupted 2-0 Vicryl sutures, and the skin was closed with interrupted 3-0 Nylon sutures. No fascial closure of these port sites was performed.

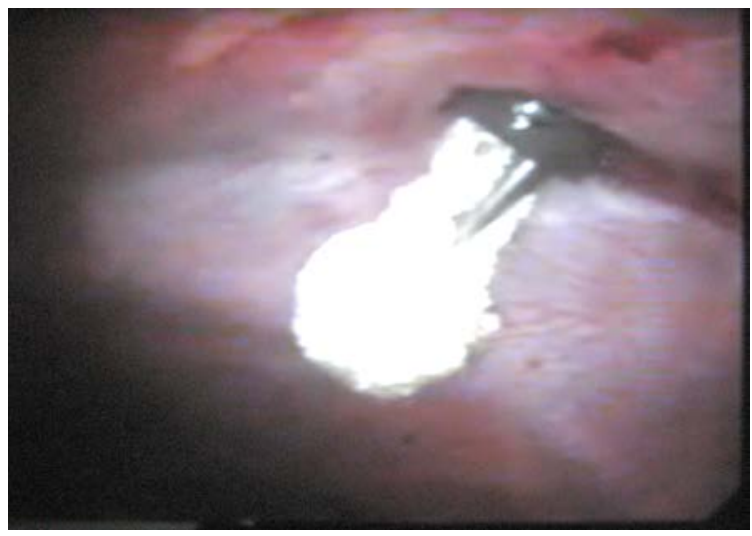

Figure (1B) 


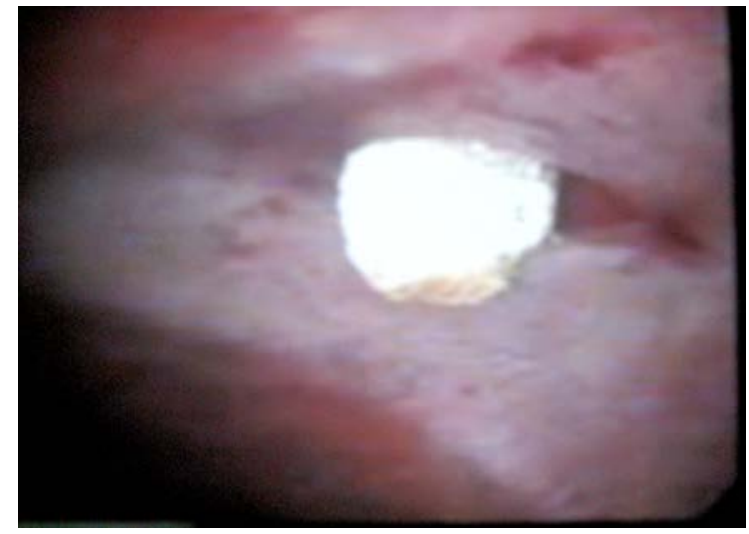

Figure (2A)

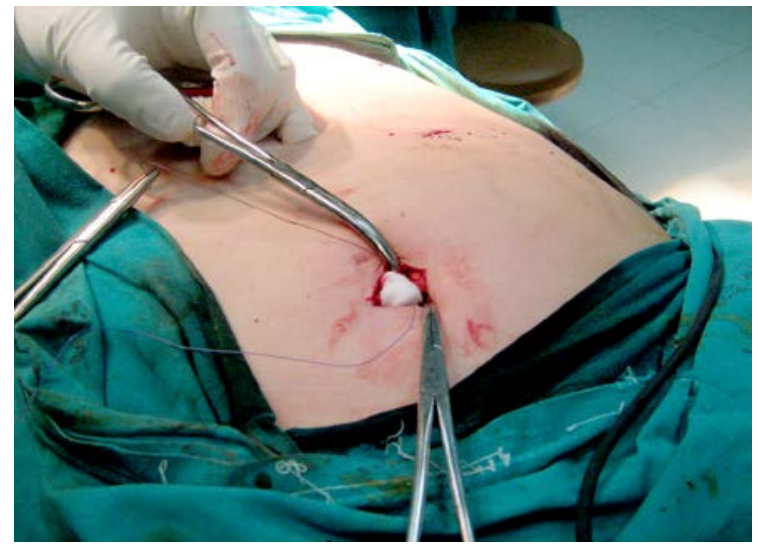

Figure (3A)

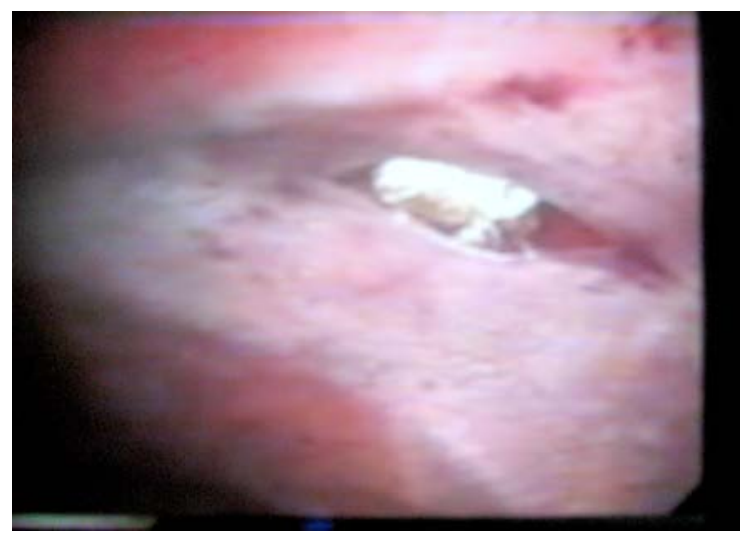

Figure (2B)

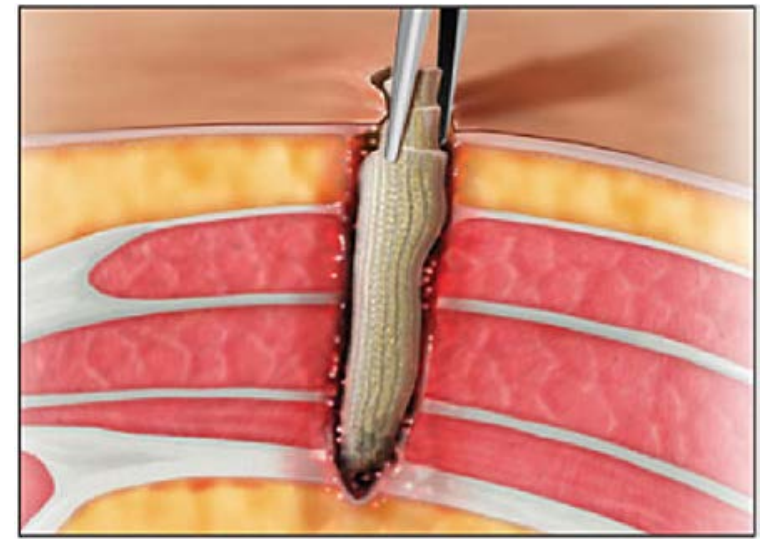

Figure (3B)

Fig. (1a): Piece of Surgicel ${ }^{\circledR}$ mesh folded a as a plug and inserted it into the abdominal cavity via the port. Fig. (1b): Withdrew the port through the muscle layer slowly. Fig. $(2 a$, $b)$ : Retraction of the Surgicel ${ }^{\circledR}$ plug, which is being left inside the muscle layer of abdominal wall. Fig. (3a): Surgicel ${ }^{\circledR}$ plug left inside the muscle layer. Fig. (3b): The port was removed (The final location of the Surgicel ${ }^{\circledR}$ plug).

Desufflation of the peritoneal cavity was completed via the supraumbilical port before it was removed. Thus, it was expected that the bowel or omentum would not be sucked into the wound with the $\mathrm{CO} 2$, just following port removal. For cases undergoing gastric bypass, we inserted the Surgicel ${ }^{\circledR}$ plug. For cases undergoing gastric banding, we sutured a piece of mesh behind the access-port of the gastric banding system for fixation to the rectus muscle; thus, we just embedded the accessport complex inside a supraumbilical wound, but no Surgicel ${ }^{\circledR}$ plug was inserted. The procedures for subcutaneous and cutaneous layer closure were the same.

\section{Results:}

At a mean follow-up time of 13 months (range 2 to 24 months) for these 109 patients, trocar wound herniation was detected in two patients; one male in the gastric bypass group, and one female in the gastric banding group for an overall prevalence of $0.33 \%(2 / 610)$. One was aged 43 and the female was aged 37. None had a history of abdominal surgery. Diabetes mellitus was present in one of these two patients. BMI was $43.4 \mathrm{~kg} / \mathrm{m} 2$ and 44.1 $\mathrm{kg} / \mathrm{m} 2$. None of them had a wound infection after the operation. The interval between surgery and diagnosis were 1 and 3 months, respectively. The hernias occurred at the 12rnm trocar wound of the left midclavicular line, $2-3 \mathrm{~cm}$ below the costal margin, outside the left rectus muscle and the other hernia at the supra-umbilical wound $(12 \mathrm{~mm})$ in the patient with Laparoscopic gastric banding Table(1). 
Table (1): Case reports of trocar site hernia (TSH).

\begin{tabular}{|c|c|c|c|c|c|c|}
\hline $\begin{array}{c}\text { Number } \\
\text { of } \\
\text { cases }\end{array}$ & $\begin{array}{l}\text { Original } \\
\text { surgery }\end{array}$ & $\begin{array}{c}\text { Chief } \\
\text { complain }\end{array}$ & $\begin{array}{c}\text { Delay } \\
\text { after } \\
\text { laparoscopy }\end{array}$ & $\begin{array}{c}\text { Main } \\
\text { clinical } \\
\text { manifestation }\end{array}$ & $\begin{array}{l}\text { Trocar } \\
\text { size } \\
(\mathrm{mm})\end{array}$ & $\begin{array}{l}\text { Hernia } \\
\text { site }\end{array}$ \\
\hline $1 / 12$ & $\begin{array}{c}\text { Lap. Roux } \\
\text { en -Y } \\
\text { gastric } \\
\text { Bypass }\end{array}$ & $\begin{array}{c}\text { Asympto } \\
\text {-matic } \\
\text { lump }\end{array}$ & 8 months & $\begin{array}{l}\text { Herniation } \\
\text { of } \\
\text { omentum }\end{array}$ & $\begin{array}{c}12 \\
\mathrm{~mm}\end{array}$ & $\begin{array}{c}\text { Left } \\
\text { upper } \\
\text { Quadrant }\end{array}$ \\
\hline $0 / 18$ & $\begin{array}{l}\text { Lap. } \\
\text { Gastro } \\
\text { plasty }\end{array}$ & ----- & $-----\cdot$ & ----- & ----- & $-----\cdot$ \\
\hline $1 / 15$ & $\begin{array}{c}\text { Lap. } \\
\text { Gastric } \\
\text { Banding }\end{array}$ & $\begin{array}{l}\text { Asympto } \\
\text {-matic } \\
\text { lump }\end{array}$ & 8 months & $\begin{array}{l}\text { Herniation } \\
\text { of } \\
\text { omentum }\end{array}$ & $\begin{array}{c}10 \\
\mathrm{~mm}\end{array}$ & $\begin{array}{l}\text { Supraum } \\
\text { bilical }\end{array}$ \\
\hline $0 / 64$ & $\begin{array}{c}\text { Lap. } \\
\text { Cholecyst } \\
\text { ectomy }\end{array}$ & $---\ldots$ & ---- &.---- & $---\ldots$ & ----- \\
\hline
\end{tabular}

A protruded soft mass was noted at these trocar wounds during abdominal muscle exertion. None developed intestinal obstruction or peritonitis, nor received subsequent operative management. In contrast, no patient in the gastric banding or gastroplasty group showed a hernia.

The follow-up rate of our database was 101/109 (92.6\%). Regarding the eight patients lost to follow-up and excluded from this study, two were lost to follow-up 1 year after the operation; they had no sign of trocar wound herniation from the data recorded.

\section{Discussion:}

Crist and Gadacz ${ }^{7}$ defined trocar-wound herniation as the development of a hernia at the trocar-cannula insertion-site of laparoscopic surgery. The reported incidence of this specific complication ranges from $0.021 \%$ to $5 \%$, with an average of $1 \%$ in most series published. ${ }^{2-5,8-15}$ However, the true incidence may be underestimated for a variety of reasons, such as failure to diagnose, delay in diagnosis, patient tolerance of an asymptomatic hernia and loss to follow-up. ${ }^{13-16}$ The wide variety of procedures and surgeons makes it difficult to analyze the true incidence. ${ }^{16-17}$

Risk factors related to trocar wound herniation may be divided into clinical and technical (mechanical) aspects. Clinical factors include male sex, advanced age, poor nutrition, anemia, diabetes, renal failure, treatment with steroids, advanced malignancy, and obesity. 3,15,18 Technical and mechanical factors include sharp-bladed trocar-tip, larger trocar size, open laparoscopy (Hasson trocar insertion), stretching the port-site during manipulation, the technique of closure, properties of the suture materials used for closure, and location of the incision. ${ }^{3-16,18}$ Some reports suggest that the main pathogenesis is not host factors but rather technical ones, and most assert that a large trocar size, a bladed trocar-tip, and leaving the fascial defect open may lead to trocar wound hernia. $^{3}$

As techniques and equipment advance, larger trocar openings are required (some instruments require trocar-sites as large as 20 $\mathrm{mm}){ }^{4-14}$ It is claimed that trocar hernias are associated with increased size of trocars. $3,4,11,19$ Montz and co-workers ${ }^{20}$ found that of 840 hernias in which the trocar size was known, $86 \%$ occurred in connection with trocars $>10$ $\mathrm{mm}$. Kadar et $\mathrm{al}^{21}$ reported an incidence of $0.23 \%$ ( 1 in 429 patients) by the application of $10-\mathrm{mm}$ trocars, rising to $3.1 \%$ (5 in 161 patients) when $12-\mathrm{mm}$ trocars were used. In the survey of the American Association of 
Gynecologic Laparoscopists, of 840 trocar wound hernias, $725(86.3 \%)$ occurred in sites where the diameter was $>10 \mathrm{~mm}$. Only 92 hernias $(10.9 \%)$ occurred at a site of insertion of ports of $8-10 \mathrm{~mm}$ in diameter, with $23(2.7 \%)$ occurring in sites where ports were $<8 \mathrm{~mm} .3,20$ It is generally recommended that fascia of 5$\mathrm{mm}$ trocar incisions not be closed, while that of 10- to 12-mm trocar incisions be closed at the end of laparoscopic procedures because of the increased risk of trocar wound hernias. $4,5,8,10,14,15$ To reduce the frequency of trocar hernias, it is recommended to apply small size trocars whenever possible. For trocar wounds $>10 \mathrm{~mm}$, it is believed that the muscular layer should be managed, and not just the subcutaneous and cutaneous layers be sutured. ${ }^{19,20}$

When non-bladed systems are used, damage is minimal, because dilation and fiber splitting are the principal mechanism of entry. ${ }^{2,5,16}$ The separated fascia generally reapproximates after port removal, much like a valve. ${ }^{16}$ Conversely, the bladed trocar perforates the abdominal wall by cutting fascia, muscle fibers, and peritoneum, and creates a defect, which constitutes a risk for hernia formation. In an animal experiment, Tarnay et $\mathrm{al}^{16}$ compared the area of the fascial defect created by insertion of six different laparoscopic trocar-cannula systems - two of blunt conical design (nonbladed), two of pyramidal design (bladed), and two of cutting-dilating design (bladed). The blunt conical trocars created smaller fascial defects than both the pyramidal mid the cuttingdilating trocars and reduced the risk of trocar wound hernia-tion. ${ }^{2,16}$ These conclusions were supported by data from Lajer et $\mathrm{al}^{11}$ who found a reduction of trocar wound herniations from $2 \%$ to $0.2 \%$ when a conical-shaped trocar was used in place of a sharp cutting trocar. ${ }^{21}$ In many other studies, it has been suggested that with the use of non-bladed trocars, closure of the fascia may not be necessary, except for an umbilical trocar. ${ }^{5,16,22,23}$
In the early development of laparoscopic surgery, some authors did not recommend routine closure of the fascial defects, while others suggested that any opening $>10 \mathrm{~mm}$ in diameter should be closed.4,11,15,16,24 Some surgeons proposed that an attempt should be made to close the fascia at the site of insertion of the umbilical port if it was $>10 \mathrm{~mm}$, but not the lateral sites. ${ }^{24}$ Studies have suggested that when the fascia was left open, the risk of trocar wound hernia formation was proportionate lo the diameter of the cannula at both the umbilical or extraumbilical sites. 16 However, Montz and associates showed, in a survey of 933 trocar hernias that $17.9 \%$ still occurred although fascial closure had been performed. ${ }^{20}$ How lo properly close a fascial defect is contentious. Gallery et $\mathrm{a}^{25}$ stated that all large trocar-sites should be closed meticulously, even if the skin incision had to be extended. Some authors even suggested that larger trocar-sites be closed completely with adequate muscle relaxation. ${ }^{3}$ Elashry et $\mathrm{al}^{4}$ recommended that closure be done with a fascial closure device (CarterThomason ${ }^{\circledR}$ device) under direct vision to ascertain adequate closure of the fascial defect. Eid and Collins ${ }^{15}$ also found that the CarterThomason closure System XLTM (Inlet Medical, Eden Prairie, MN, USA) resulted in a superior closure, both in terms of operative lime and patient outcomes Figure(4A,B,C,D). Besides, it achieves a full-thickness trocar wound closure, not just the fascial layer. ${ }^{13}$ However, some surgeons believe that use of such devices is time-consuming and costly while still without guarantee of a hernia-proof closure, especially in the obese. ${ }^{5}$ While others advocates Z" trocar insertion for all abdominal trocar perforations to avoid later hernias Figure(5). ${ }^{18}$ 


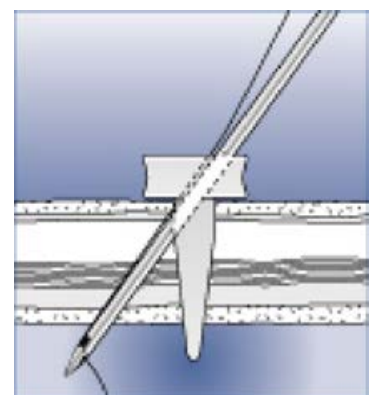

Figure (4A)

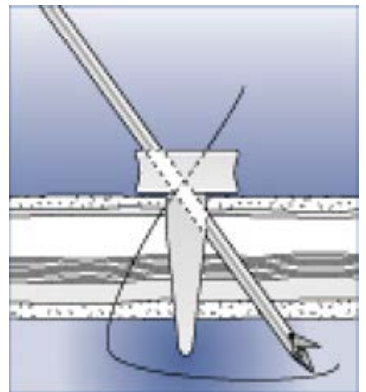

Figure (4B)

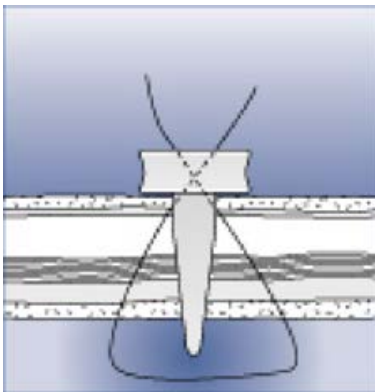

Figure (4C)

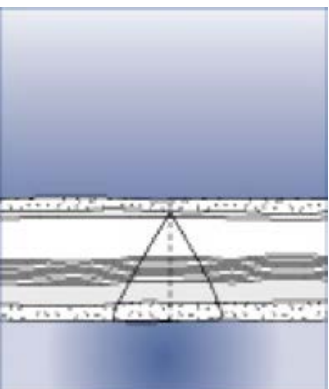

Figure (4D)

Figure (4): Carter-Thomason closure System; (a): Drop the suture, and remove the suture passer. (b): Push the suture passer through the opposite side of the guide and pick up the suture. (c): Pull the suture up through the peritoneum, muscle, fascia. $(d)$ : Remove the tie.

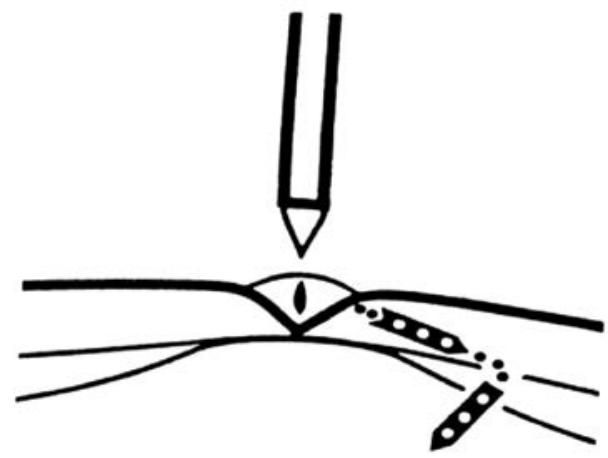

Figure (5): Z" trocar insertion for abdominal trocar perforations to avoid later hernias (copied from The American Journal of Surgery: port sites, Volume 191, Issue 1, Pages 114).

In morbidly obese patients who underwent laparoscopic bariatric surgery, initial studies found a decreased wound complication rate (infection, hernia) compared to historical results from laparotomy. $5,15,26$ Obese patients are at a high risk for preperitoneal hernias because of their elevated intra-abdominal pressure and substantially thicker fatty preperitoneum. ${ }^{3,11}$ Besides, this thick fatty preperitoneum is potentially a space for intestinal incarceration, with the peritoneum acting as the strangulating ring, despite adequate fascial closure. ${ }^{8,15}$ Also, it is not easy to securely close the fascial defect in morbidly obese patients.

The presenting technique performs no fascial closure of all trocar-site wounds after port removal. Instead, we fold a small piece of Surgicel ${ }^{\circledR}$ mesh as a plug and insert it into the muscle layer of trocar wounds of $10-\mathrm{mm}$ and 12-mm size.

Surgicel ${ }^{\circledR}$ mesh, an oxidized regenerated cellulose hemostat, has proven to be a safe and reliable product that offers some advantages over other topical hemostatic agents including ease of use, efficacy on many types of bleeding surfaces, antibacterial action, biocompatibility, and trivial mass effect. ${ }^{27-29}$ In an animal study, when inserted into the muscular layer, the Surgicel ${ }^{\circledR}$ served as a barrier preventing intestinal herniation; it did not incite an inflammatory or foreign body reaction, and it retarded the formation of adhesions with the intestine. ${ }^{29}$ Another study revealed that the average time of trocar wound herniation was within 10 days after operation. ${ }^{14-15}$ Surgicel $Æ$ has been found to clear from the implantation site in 1 week, which is likely adequate for separated muscle fiber healing and approximation. $^{29}$

In open abdominal surgery, prophylactic use of mesh as a solution for incisional hernia has gained wide popularity. ${ }^{30-32}$ The initial result of trocar wound herniation was $0.08 \%$ $(1 / 12)$ in patients with gastric bypass and in gastric banding was $0.06 \%(1 / 15)$. Compared to other-studies with Roux-en-Y gastric bypass $(0.3 \% 30$ to $1.0 \% 31)$ and gastric banding $(0.4 \% 32)$, the short-term results appears favorable. ${ }^{33}$ However, a randomized prospective comparison with other techniques is required to determine long-term benefits. 
Laparoscopic surgery offers obese patients greater comfort in the postoperative period, short hospital stay and quick return to physical activities. ${ }^{1}$ However, postoperative hernia may still be an infrequent complication. This method of Surgicel ${ }^{\circledR}$ plug insertion may have theoretical advantages, and can be applied safely in patients with high risk for trocarwound hernia.

\section{References:}

1- Chu UB, Adrales GL, Schwartz RW et al.: Laparoscopic incisional hernia repair: A technical advance. Curr Surg 2003; 60: 287-291.

2- Bowrey DJ, Blorn D, Crookes PF et al.: Risk factors and the prevalence of trocar site herniation after laparoscopic fundoplication. Surg Endosc 2001; 15: 663-666.

3- Tonouchi H, Ohmori Y, Kobayashi M et al.: Trocar site hernia. Arch Surg 2004; 139: 1248-1256.

4- Elashry OM, Nakada SY, Wolf JS Jr et al.: Comparative clinical study of port-closure techniques following laparoscopic surgery. J Am Coll Surg 1996; 183: 335-344.

5- Shalhav AL, Barrel E, Lifshitz DA et al.: Transperitoneal laparoscopic renal surgery using blunt $12-\mathrm{mm}$ trocar without fascial closure. Endourol 2002; 16: 43-46.

6- Wang W, Wei PL, Lee YC et al.: Shortterm results of laparoscopic mini-gastric bypass. Obes Surg 2005; 15:648-654.

7- Crist DW, Gadacz TR: Complications of laparoseopic surgery. Surg Clin Noith Am 1993; 73: 265-289.

8- Matthews BD, Heniford BT, Sing RF et al.: Preperitoneal Richter hernia after a laparoscopic gastric bypass. Surg Laparosc Endosc Percutan Tech 2001; 11:47-49.

9- Leung TY, Yuen PM: Small bowel herniation through subumbilical port site following laparoscopic surgery at the time of reversal of anesthesia. Gynecol Obstet Invest 2000; 49: 209-210.

10-Eltabbakh GH: Small bowel obstruction secondary to herniation through a $5-\mathrm{mm}$ laparoscopic trocar site following laparoscopic lymphadenectomy. Hur J Gynaceol Oncol 1999; 20: 275-276.
11-Lajer H, Widecrantz S, Heisterberg L: Hernias in trocar ports following abdominal laparoscopy: a review. Acta Obstet Gynecol Scand 1997; 76: 389-393.

12-Nakajima K, Wasa M, Kawahara H et al.: Revision laparoscopy for incarcerated hernia at a 5-mm trocar site following pediatric laparoscopic surgery. Surg Laparosc Endose Percutan Tech 1999; 9: 294-295.

13-Munro MG. Laparoscopic access: complications, technologies, and techniques. Curr Opin Obstet Gynecol 2002; 14: 365-374.

14-Bemporad JA, Zreik TG, Brink JA: Laparoscopic hernias: Two case reports and a review of the literature. J Comput Assist Tomogr 1999; 23: 86-89.

15-Bid GM, Collins J: Application of a trocar wound closure system designed for laparoscopic procedures in morbidly obese patients. Obes Surg 2005; 15: 871-873.

16-Tarnay CM, Glass KB, Munro MG: Incision characteristics associated with six laparoscopic trocar-cannula systems: A randomized, observer-blinded comparison. Obstet Gynecol 1999; 94: 89-93.

17-Buyere F, Sun J, Cosson JP et al.: Incarceration of bowel through opening of a 5-mm port. $J$ Endourol 2004; 18: 675676.

18-Brolin RE: Prospective, randomized evaluation of midline fascial closure in gastric bariatric operations. Am J Surg 1996; 172: 328-331.

19-Kurtz BR, Daniell JF, Spaw AT: Incarcerated incisional hernia after laparoscopy. J Reprod Med 1993; 38: 643-644.

20-Montz FJ, Holschneider CH, Munro MG: Incisional hernia following laparoscopy: A survey of the American Association of Gynecologic Laparo-scopists. Obstet Gynecol 1994; 84: 881-884.

21-Kadar N, Reich H, Liu CY et al.: Incisional hernias after major laparoscopic gynecologic procedures. Am J Obstet Gynecol 1993; 8: 171-178.

22-Lowry PS, Moon TD, D'Alessandro A: Symptomatic port-site hernia associated with a non-bladed trocar after laparoscopic live-donor 
nephrectomy. J Endourol 2003; 17: 493-494.

23-Liu CD, McFadden DW: Laparoscopic port sites do not require fascial closure when nonbladed trocars are used. Am Surg 2000; 66: 853-854.

24-Reissman P, Shiloni E, Gofrit O et al.: Incarcerated hernia in a lateral trocar sitean unusual early postoperative complication of laparoscopic surgery. Eur J Surg 1994; 160: 191-192.

25-Gallery MP, Strasberg SM, Soper NL: Complications of laparoscopic general surgery. Gastrointest Endose Clin N Am 1996; 6:423-444.

26-Deitel M, Alhindawi R, Yamen M et al.: Dexon plus versus Maxon fascial closure in morbid obesity: A prospective randomized comparison. Can J Surg 1990; 33: 302-304.

27-Kuchta N, Dineen P: Effects of absorbable hemostats on intra-abdominal sepsis. Infec in Surg 1983; 441-445.

28-Sabel M, Stummer W: The use of local agents: Surgicel and Surgifoam. Eur Spine J 2004; 13: 97- 101.
29-Arnar AP, Levy ML: Applications of topical hemostatic agents in neurosurgery. Contemp Surg for Residents 1996; 4: 19-22. 30-Schauer PR, Ikramuddin S, Gourash W et al.: Outcomes after laparoscopic Roux-enY gastric bypass for morbid obesity. Ann Surg 2000; 232: 515-529.

31-Dresel A, Kuhn JA, Westmoreland MV et al.: Establishing a laparoscopic gastric bypass program. Am J Surg 2002; 184: 617-620.

32-Chevallier J-M, Zinzindohoue F, Douard $\mathrm{R}$ et al.: Complications after laparoscopic adjustable gastric banding for morbid obesity: Experience with 1,000 patients over 7 years. Obes Surg 2004; 14: 407 414.

33-Holzinger F, Klaiber C: Trocar site hernias. A rare but potentially dangerous complication of laparoscopic surgery. Chirurg. 2002; 73(9):899-904. 